\title{
Application Technology and Development Trend of Construction Machinery Automation
}

\author{
Wenxia Zhu \\ Xi'an International University, Shaanxi Xi'an 710077
}

Keywords: construction machinery; automation technology; development trend

\begin{abstract}
In recent years, with the continuous improvement of science and technology and rapid economic development, people's quality of life and material production and the level of material and cultural needs are increasingly diverse. In such a demand and technical support, construction machinery automation should be born. In modern life, computer technology has penetrated into all aspects of our daily lives. How to make better use of construction machinery automation and promote the construction machinery automation to a stronger direction needs to face and solve the problem. In order to promote the application of building automation and promote the development of China's construction machinery automation, this paper focuses on the construction machinery automation research and analysis, from the status, characteristics, key technology, application of construction machinery automation in China construction industry and the significance of automation technology and other angles to analyse the future development trend of China's construction machinery automation.
\end{abstract}

\section{Introduction}

From the perspective of the construction industry, under the existing technical conditions and economic conditions, China's construction continue to be safe, efficient, time-saving, high-quality and comfortable direction. Although, the traditional construction machinery has been able to achieve mechanized construction, but there are still many limitations. For example, the construction of labour intensity, poor construction comfort, low productivity and the quality of construction are not guaranteed, etc., and there is a big gap inhuman requirement, which is not being mentioned. There are often accidents and so on. If we want to change the status, can we only continue to strengthen China's construction machinery automation technology applications and promote China's construction machinery automation technology and international standards and able to occupy an advantageous position in the international competition.

\section{The Basic Overview of Mechinery Automation Technology}

Mechanical automation technology refers to a computer technology and control theory as the core of a comprehensive technology. With the continuous progress of science and technology and the rapid development of computer technology, mechanical automation technology came into being. It is reported that the use of mechanical automation technology is the life of the parameters used as a reference basis, the use of modern technology and equipment reduced human and capital investment and waste and is full use of mechanization instead of manpower design and manufacture, commissioning, maintenance Wait. Today, mechanical automation technology has been fully and widely used in various industries and fields ${ }^{[1]}$.

\section{The Application Status and Existing Problems of Construction Machinery Automation}

China's construction machinery automation research and development can be traced back to the fifties and sixties in the last century. To the last century in late eighties, construction machinery automation development and application of the pace has been accelerating. According to the relevant investigation and analysis, in the current actual construction projects, they have been 
widely used in construction machinery automation technology equipment mainly paver, electronic detection and control system PIC, automatic monitoring. Among them, the paver has to ensure that the vertical and horizontal alignment of the automatic levelling function and can also control the thickness of the paving layer, but also with a mixture of automatic feeding device, automatic adjustment system; and electronic detection control system is an automatic bulldozer on the main use of the electronic detection control system; there are hydraulic excavators on the latest load detection, automatic idling, fault diagnosis and electronic control function of the way to achieve automatic monitoring of bulldozers ${ }^{[2]}$. The following paper describes the actual application of building automation technology in the case of the actual situation.

\subsection{The application of automatic roller in reservoir dam}

It is known that the automatic roller in the reservoir dam has been widely used. For example, in a river dam concrete construction, automatic roller is the most commonly used mechanical equipment. And the automatic roller used in this project has already introduced the automatic detection device, the related data processing device, the central control system as well as the long-distance communication device and so on, this automatic road roller instalment chart like chart 1 shows. It is reported that this automatic roller will be applied to the construction of the river dam through the light wave distance measurement device and airborne automatic tracker on the work of the roller position of the pre-determined and default ground reference point. According to the realization of the work process, the measured location data can be sent through the data processing device processing in the communication module under the effect of transmission to the central control system. The use of this automatic roller and other related systems, technologies and devices not only improves the accuracy of the data in this construction, but also speeds up the construction and improves the accuracy of construction to ensure that the large-scale and we need to make sure this work can be completed on a regular basis with good quality and quantity.
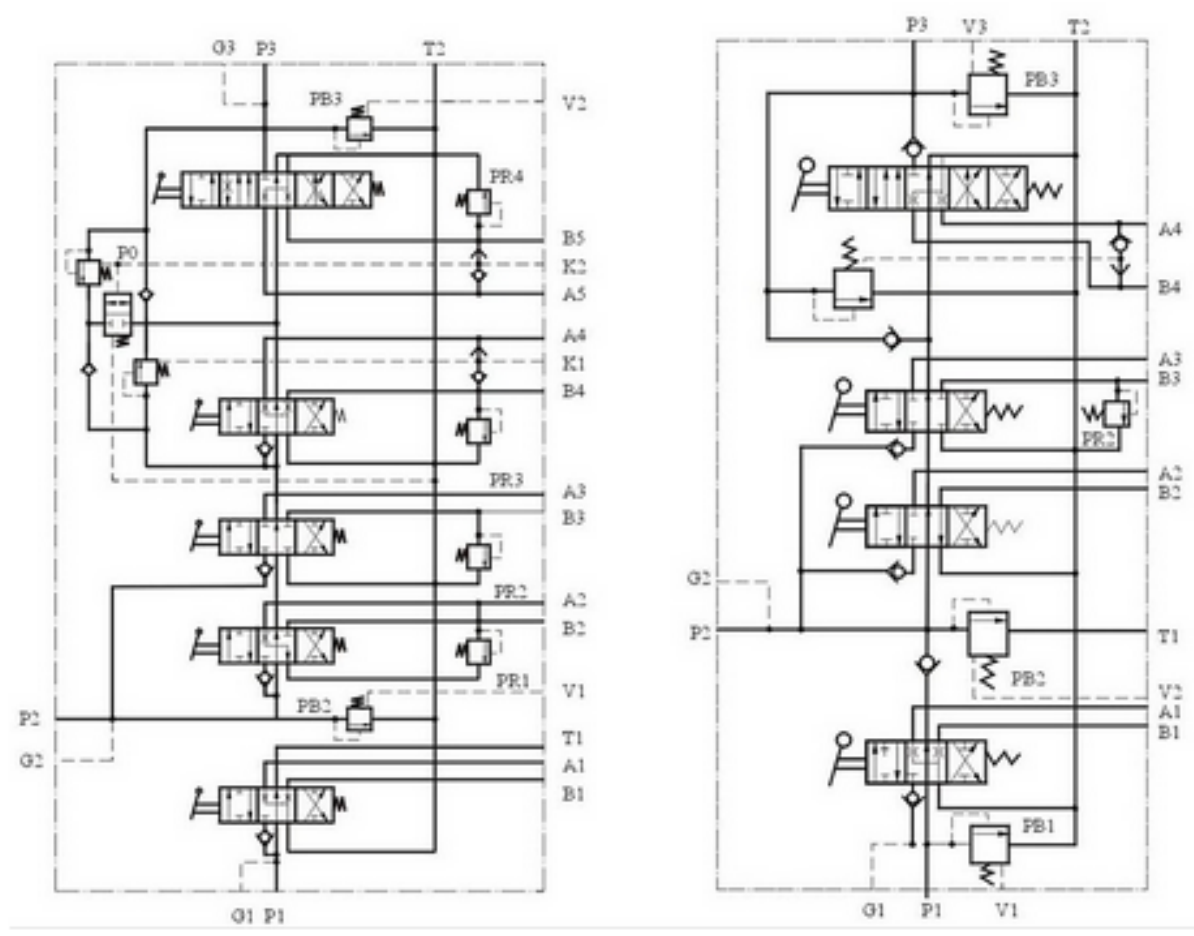

Fig.1 Device of automatic roller

\subsection{Bulldozer and excavator operations achieve automation}

The biggest effect of automation between bulldozers and excavators is: significantly improve the bulldozers and excavators construction quality and efficiency. The earliest automation devices that appeared in excavators were the automated control systems used on the shovels of excavator buckets and bulldozers. The main structure of the system includes the emitter, photoreceptor and 
control system. However, the early automation control system still has many problems, so it has not been widely promoted and widely used. Then the KOMATSU Laser levelling system was applied to bulldozers and excavators. It is reported that the bulldozer reset the system in a project in the application of the project directly to the construction bulldozer flatness error remained at $3 \mathrm{~m}$, and its speed is $5 \mathrm{~km} / \mathrm{h}$. The excavator is cited in the hydraulic excavator laser automatic excavation system, laser automatic excavation system, including automatic linear processing system and laser system in two parts. The laser system can detect the height of the vehicle body of the relevant equipment and measure the specific position of the working surface by laser sensor. Then the data and information are processed and transmitted to the automatic digging system. Finally, the integrated system of the information and the sensor signal form the electromagnetic proportional valve control commands, the final realization of the control and detection of the cylinder ${ }^{[3]}$.

From the above example analysis can be seen, so far, although China's construction machinery automation has entered the development of state, breaking the zero situation of construction machinery automation, there are still many problems. For example, China's construction machinery automation technology level is still in the low-end state. With the rapid development in decades, but there is still a big gap between the developed countries and developed countries which are more intelligent, flexible and integrated. China's construction machinery automation is still in the automation and rigidity of the list Automated on the horizon. Another major problem is that China's construction machinery automation technology existing in small talent attention, such as large vacancies in professional issues. The lack of relevant professionals is the biggest obstacle to the development of mechanical automation, automation technology will lead to stagnation. Of course, in the application of building automation technology, the prominent problems also include the application of China's construction machinery automation which is widely limited. These restrictions include the environment and financial constraints on the technology, once the technical requirements increases; it also is being more difficult.

\section{Key Technology of Construction Machinery Automation}

Mechanical automation is also applied into construction; we must take the construction of terrain, environmental constraints into account. Therefore, we need to ensure that construction machinery automation can be unimpeded, unrestricted application with the following key technologies.

First, it is construction machinery of the fuselage location recognition technology. The technology can automatically identify the location and environment of the machine by its own equipment. This body position recognition technology includes internal location recognition technology and external device identification. The two types of identification can be achieved through the speed sensor and rotary angle sensor with each other to achieve the internal device identification.

Second, the position-inducing function. The position inducing function is based on the feedback data of the fuselage position identification system, and the work is carried out according to the pre-set working path, and then calibrated or eliminated according to the specific working conditions. The error of the operating path, which constitutes the entire closed-loop control technology system, can ensure that the equipment can be real-time position, speed and direction of correction and recovery.

Again, the job objects recognition and evaluation techniques. The importance of recognition technology has already been addressed in the previous section, and will not be discussed here. Looking at the evaluation technology, with the evaluation technology of clear and accurate information, we can timely understand the construction of real-time operating conditions and quality, so that the corresponding post-adjustment can ensure the quality of construction operations.

Finally, the security functions. As the construction site environment, there are a lot of building materials and operating equipment and so on. These obstacles increase a certain degree of difficulty of the construction of machinery and equipment, in order to be able to ensure the construction process of mechanical equipment can operate effectively at the same time. We need a set of identification, alarm and stop operations to ensure that the security zone induction control statistics. 


\section{The Development Trend of Construction Machinery Automation Technology}

First of all, from the present stage of China's construction machinery automation technology and the status of the problem, it is necessary to change the current status to solve the problems at this stage. First, we must continue to improve the technical level of China's construction machinery automation, and strive for an early convergence with international standards; the second is to cultivate more specialized, specialized personnel to ensure that talent reserves to keep up with the pace of development of mechanical automation technology; To increase capital investment, breaking the current restrictions on the application of mechanical automation technology, continue to promote and expand the scope of application of construction machinery automation technology and application industries. From a comprehensive point of view, China's construction machinery automation of the future development trend are the following aspects:

(1) The basic overview of mechanical automation technology

Practical development of nature is the primary direction of development. Because the ultimate goal of construction machinery automation technology is the application, in order to be able to fully apply the automation technology to the construction industry which is bound to need to be practical direction is the ultimate goal.

(2) The development of automation technology in line with China's national conditions

Although the developed countries are very high-end machinery automation, but due to specific national conditions, and the purpose of mechanical and automation technology development is applied to China's construction industry which is bound to need to meet our national conditions Coaxing.

(3) High-efficiency, low-cost automation technology

Applying mechanical automation technology to the construction industry, there are a large number of reasons is to save manpower, material and financial resources to improve the efficiency of building construction. Therefore, the future development direction of China's construction machinery automation technology must be to continuously improve the mechanical automation technology in the construction industry which high efficiency, while continuously reducing construction costs, achieve high efficiency and low cost of unity.

(4) The green development of mechanical automation technology

Now the direction of social development is sustainable, green development. In recent years, the rapid development of society accompanied by the serious destruction of human living environment, resource and environmental development problems is becoming more and more serious. Mechanical manufacturing industry as a pillar of the future industry, naturally cost a lot of social resources, and seriously affects the environmental problems. If you want to change the serious shortage of resources and environmental pollution problems, we need to take a healthy, green and sustainable development path.

\section{Conclusion}

In short, to break the status of China's construction machinery automation technology and the current situation, to narrow the gap with the developed countries in the mechanical automation technology, first of all to realize that the current application of mechanical automation technology in the construction of the status and problems. Second, we must focus on solving existing problems, and then analyze the key technology of mechanical automation, and finally to the green, low-cost, and efficient mechanical automation technology direction [4].

\section{References}

[1] Mechanical manufacturing automation technology characteristics and development trends [J]. Peijie Liu. Private technology, 05: 67, 2014.

[2] Analysis of mechanical engineering automation control technology [J]. Xiuhuan Tang . Private Science and Technology, 01: 45, 2015. 
[3] Mechanical automation in the construction of the application [J]. Weibing Xing. Mechanical and electrical engineering technology, 07: 231-232, 2015.

[4] Mechanical and electrical automation in the construction machinery manufacturing application [J]. Xiaocun Huang, Xuxin Liu, Xiaodong Zhao, etc. Heilongjiang Science and Technology Information, 09: 153, 2016. 